Psicologia \& Sociedade; 14 (1): 103-122; jan./jun.2002

\title{
REESTRUTURAÇÃO PRODUTIVANO SETOR BANCÁRIO BRASILEIRO E SOFRIMENTO DOS CAIXAS EXECUTIVOS: UM ESTUDO DE CASO
}

\author{
Álvaro Roberto Crespo Merlo \\ Neuzi Barbarini
}

Universidade Federal do Rio Grande do Sul

RESUMO: este artigo tem por objetivo apresentar uma análise das repercussões das mudanças no psiquismo em trabalhadores que desempenham a função de caixas de um grande banco estatal brasileiro em processo de reestruturação produtiva, com uma atenção particular às formas de mobilização da inteligência, da personalidade no trabalho e na utilização de estratégias coletivas de defesa para enfrentar o sofrimento. Foi utilizada para a pesquisa e a análise dos dados, a metodologia da Psicodinâmica do Trabalho, disciplina que estuda em que situações as condições organizacionais determinam o sentido e a mobilização subjetiva no trabalho, e também as repercussões dessas condições sobre a saúde dos trabalhadores. Foi constatado que a mobilização psíquica provocada pelas mudanças é intensa, a partir de sentimentos de insegurança, estranhamento, desorientação e impotência diante das incertezas das propostas da empresa, sendo a perda do contato com o cliente uma das maiores fontes de sofrimento para o grupo. Há um sentimento de desvalorização, manifestado nas queixas sobre o achatamento salarial, na perda do status que a função proporcionava e na desestruturação de um saber acumulado ao longo dos anos de exercício da função. O sofrimento psíquico dos caixas, provocados pelas reestruturações no trabalho, atingem níveis preocupantes, pois as novas formas de organização do trabalho estão destruindo a imagem do caixa como um profissional e reduzindo a possibilidade de serem reconhecidos pelo exercício da atividade.

PALAVRAS-CHAVE: Psicologia social - trabalho, Trabalho - aspectos psicossociais. 
Merlo, A.L.C.; Barbarini, Neuzi. "Reestruturação produtiva no setor bancário brasileiro e sofrimento dos caixas executivos: um estudo de caso"

\section{RESTRUCTURING IN THE WORK OF BRAZILIAN BANKS AND THE CONSEQUENCES ON THE PSYCHE OF THEIR WORKERS}

ABSTRACT: the objective of this article is to study the consequences in the work in Brazilian banks after the deep changes, mainly after the implementation of the economical plan from 1994 - "Plano Real". In their efforts to adapt themselves to the new economical contingency of the country and to the increase in competition in this sector, the banks have restructured their organisations, downsized their staff, replaced workforce for computerizing systems which allow the treatment of data using less workers. These changes have not occured without consequences for the workers. These people have had to adapt themselves to the new situation, to the increase of pressure of work, of the exposure to risks and, to the end of job stability. Based on a research carried out with cashiers from a bank, an analysis of the repercussion of those changes for the workers' psyche was done with particular attention to the ways of the mobilization of intelligence and of their personality in the work and in the use of collective strategies of defence to fight the suffering. In order to carry out the research and to analyse the data, we have used the theoretical and methodological approaches of the Psychodynamics of Work, a subject which studies in which situations the conditions of the organisations determine the direction and the subjective mobilization in the work as well as the consequences of those conditions on the workers' health.

KEY WORDS: productive restructuring, psychodynamics of work, workers' health.

\section{INTRODUÇÃO}

Uma das atividades onde o trabalho tem se transformado de forma mais dramática hoje é o trabalho bancário. Esse setor tem mudado muito nos últimos anos. Qualquer pessoa que esteja habituada a fazer uso desses serviços certamente percebe muitas dessas mudanças no seu dia-a-dia, seja na infra-estrutura disponibilizada a clientes e funcionários - como a automação e as instalações físicas - seja em mudanças no funcionamento interno das agências, na forma de atendimento aos clientes e na natureza dos produtos oferecidos. Essas transformações começaram a ocorrer de forma mais acelerada sobretudo após a implantação do Plano Real, em 
Psicologia \& Sociedade; 14 (1): 103-122; jan./jun.2002

1994 e vem produzindo, também, transformações importantes na organização do trabalho, com dispensa de pessoal, novas formas de uso e gestão da força de trabalho e aumento das exigências de qualificação e de comprometimento dos trabalhadores.

Como a efetivação das mudanças geralmente exigem uma mobilização dos trabalhadores, decidimos enfocar este estudo na forma como um coletivo de trabalhadores as vivenciam no cotidiano e, para isso, optamos por trabalhar com um grupo de caixas executivos (caixas executivos é o nome dado aos empregados que atuam como caixas bancários na instituição pesquisada), visto que esta é uma das funções que mais tem sofrido mudanças no seu trabalho.

Para proceder a análise, utilizamos o referencial teórico da Psicodinâmica do Trabalho, que relaciona a organização do trabalho com a possibilidade de obter prazer ou sofrimento no trabalho, dando especial atenção às condições de mobilização da inteligência e da personalidade do trabalhador no seu trabalho. Esta abordagem conjuga questões relativas à significação e à vivência subjetiva das pessoas no trabalho e questões relacionadas à organização e às relações sociais no trabalho, compreendendo o sofrimento à partir de uma perspectiva da normalidade e não da patologia, considerando o trabalho como centro da luta do sujeito para preservar a saúde mental

Assim, enfocaremos neste artigo a maneira como os trabalhadores vêem e sentem essa reestruturação, e como ela desencadeia um movimento coletivo de defesa para possibilitar a manutenção da saúde mental.

\section{REESTRUTURAÇÃO DO TRABALHO BANCÁRIO NO BRASIL}

A análise do trabalho bancário no Brasil, realizada por diversos autores (Garcia, 1999; Grisci, 2000; Jinkings, 1995; Larangeira, 1997; Segnini, 1998), aponta para uma desqualificação do trabalhador devido ao desenvolvimento tecnológico e mudanças nas formas de gestão. Os autores mostram que o domínio do saber da profissão, existente antes da década de 30, foi degradando-se com o início da mecanização e intensificandose com a introdução dos computadores, estando esse processo intensamente ligado à configuração econômica e social do período.

Desde a Reforma bancária de 1964, o volume de serviços prestados pelos bancos cresceu intensamente, em função do crescimento econômico e da diversificação dos serviços prestados. Os bancos passaram a receber tributos e contribuições da previdência social, a fazer operações 
Merlo, A.L.C.; Barbarini, Neuzi. "Reestruturação produtiva no setor bancário brasileiro e sofrimento dos caixas executivos: um estudo de caso"

de cobrança, venda de seguros, administração de diferentes tipos de investimentos e a oferecer linhas de crédito, entre outros serviços.

Em 1986, o governo iniciou a implantação de políticas econômico-financeiras (Plano Cruzado) para estabilizar a economia, conter a inflação e os lucros financeiros. Começou, então, uma intensa reestruturação operacional nos bancos, de forma a conseguir manter o lucro sem a chamada "ciranda financeira", que permitia o lucro fácil. Essa reestruturação compreendeu a redução do custos operacionais, com racionalização e otimização do uso da informática, fechamento de agências, exclusão das contas pequenas, consideradas não-rentáveis, demissões progressivas de funcionários e terceirização de diversas atividades.

No que se refere à automação, houve um forte investimento na migração do maior número possível de transações bancárias para o ambiente de microcomputadores, que permitem conexões eletrônicas diretas dos clientes com o banco (home-banking, office-banking, internetbanking), ou em salas de auto-atendimento, estrategicamente localizadas fora da agência, o que contribuiu para que as agências diminuíssem de tamanho e tornarem-se pontos de negócio com atividades altamente especializadas.

A estrutura operacional e de gestão dos bancos também se modificou nessa fase da automação (Larangeira, 1997). Houve uma maior ênfase no trabalho em equipe, com maior poder decisório para os empregados e também para a qualidade do atendimento. Ocorreu uma tendência a diminuição dos níveis hierárquicos para dois níveis, ou seja, as funções de gerentes e atendentes, sendo que as funções de atendentes deverão ser eliminadas no futuro e todos deverão desempenhar a função de gerente, constituindo equipes de vendas e negócios, de forma que o cliente possa realizar todas as operações com o mesmo funcionário.

Para cumprir suas novas funções, esse bancário deveria ser bem mais qualificado, com amplo conhecimento do mercado financeiro, domínio de tecnologia para realização de simulações financeiras, habilidade de relacionamento com clientes e com a equipe de vendas e precisaria saber lidar com tarefas não prescritas, diferentemente das exigências anteriores nas quais deveria seguir fielmente o manual.

Se, por um lado, houve aumento da qualificação do profissional bancário nessa fase, por outro houve aumento da carga de trabalho e das pressões. A realização dos treinamentos passou a ser feita fora do horário de trabalho e em finais de semana e grande parte dos processos de requalificação, que anteriormente eram oferecidas pela empresa, passa- 
ram a ser de responsabilidade do trabalhador e tornaram-se pré-requisitos para promoções, novas contratações e até para a sua manutenção no emprego.

Mudanças significativas no status da profissão de bancário também puderam ser observadas. Do bancário possuidor de um métier nos anos 60 (Segnini, 1998), que conhecia toda a amplitude do trabalho, passou-se ao trabalho fragmentado, rotineiro e com altas taxas de rotatividade dos anos 70-80 e início dos anos 90, em geral exercido por jovens sem expectativas de permanecer na atividade, o que contribuiu para a degradação do status da profissão.

\section{METODOLOGIA}

A Psicodinâmica do Trabalho é uma abordagem que propõe uma compreensão da relação subjetiva que os trabalhadores têm com seu trabalho, com atenção especial às formas de mobilização da inteligência e da personalidade no trabalho. O campo de pesquisa dessa disciplina busca compreender como as pessoas, sujeitas às mais diversas pressões no trabalho, conseguem evitar a doença e a loucura. Trata-se, portanto, de desenvolver uma investigação pautada na normalidade e não na doença mental. A normalidade aqui não é concebida como simples ausência de doença e de sofrimento, mas como resultado precário de estratégias defensivas elaboradas para resistir àquilo que, no trabalho, é desestabilizante e mesmo nocivo para o funcionamento psíquico e a saúde mental (Dejours, 1992).

Assim, o que é chamado de normalidade enigmática só se mantém através do recurso às estratégias defensivas, que são singularizadas em função do passado, da história e da estrutura da personalidade de cada pessoa. Para Dejours (1992, p.157), o trabalho oferece ao sujeito uma ocasião de realizar seu questionamento interior e traçar sua história, pois "a ressonância simbólica aparece como a condição necessária para a articulação bem sucedida da dicotomia singular com a sincronia coletiva".

O conceito psicanalítico de sublimação tem um papel importante para essa metodologia, entendido como um processo graças ao qual as pulsões de natureza sexual são redirigidas para uma atividade socialmente valorizada, resultando em um aumento da eficiência psíquica. O desafio do sujeito, então, é de encontrar uma via de escape para suas pulsões, que seja compatível com a sua inserção social e através da qual ele possa construir sua história pessoal.

Segundo Dejours (1992, p.134), existem alguns requisitos para 
Merlo, A.L.C.; Barbarini, Neuzi. "Reestruturação produtiva no setor bancário brasileiro e sofrimento dos caixas executivos: um estudo de caso"

que essa sublimação ocorra. É necessário que o sujeito seja capaz de mobilizar sua curiosidade (epistemofilia) em relação à situação de trabalho (o qual geralmente possui algo de enigmático), tentando compreender a realidade de forma a provocar uma diminuição do sofrimento e possibilitar sublimação. Para isso, a tarefa deve ter algum sentido para o sujeito, pois nem todas as situações de trabalho são favoráveis à sublimação. É necessário que, entre a organização do trabalho prescrita (normas operatórias, regulamentos) e a organização do trabalho real, exista um espaço que permita o desenvolvimento de alguma atividade de concepção em que o trabalhador possa assumir responsabilidades (Daniellou et alii, 1989).

Para enfrentar o inesperado, o que escapa à prescrição, o trabalhador deve lançar mão de recursos próprios, servindo-se de macetes ou burlas - como uma tradução para a palavra francesa "triche", conforme utilizado por Merlo (1999) -, desenvolvidos pelos próprios trabalhadores, que facilitam a execução das tarefas. Esses macetes ou burlas possuem uma articulação coerente e, muitas vezes, vão constituir regras de trabalho ou de ofício, tornando-se os verdadeiros reguladores para a ação e gestão das dificuldades encontradas na execução do trabalho.

Este autor destaca, ainda, a importância do reconhecimento para minimizar o sofrimento decorrente do conflito existente entre a organização real e a prescrita. O reconhecimento está no centro da construção da identidade, pois cada trabalhador possui um desejo de realizar coisas e de se auto-realizar e para isso ele vai investir seus esforços, tentando expressar o que ele é e o que quer ser.

Para que essa busca identitária se realize, é necessário que haja o julgamento de sua contribuição no trabalho, das qualidades e originalidades impressas no fazer. Esse julgamento não se reporta diretamente à pessoa, mas ao fazer e pode vir tanto da hierarquia (chefes), como dos pares (colegas de trabalho). $\mathrm{O}$ reconhecimento dos pares geralmente possui mais credibilidade, pois estes sabem o quanto de esforço e talento é necessário para se atingir o objetivo.

Esse processo de sublimação, na forma como é entendido pela Psicodinâmica do Trabalho, possui então requisitos não analisados pela Psicanálise, que são as condições de validação social, sem a qual a sublimação não ocorre.

O sofrimento no trabalho não pode ser totalmente eliminado, pois é parte da atividade e condição para que ela ocorra, mas pode ser subvertido através da sublimação e transformado em criatividade e em saúde. Isso pressupõe uma organização do trabalho que tolere os espaços informais 
de deliberação, necessários para dar visibilidade ao trabalho real. Quando a organização do trabalho é desfavorável a essa ocorrência, surge o sofrimento patogênico, este, sim, poderá trazer consequiências graves para a saúde do sujeito.

Uma organização prescrita muito rígida, que não abre espaços para questionamentos mesmo quando os procedimentos parecem absurdos, representam uma situação problemática. Se as regras são desprovidas de sentido, o trabalhador não pode investir nelas seu desejo de realização e ser reconhecido por ações sem significado pode conduzir a pessoa ao desinvestimento na atividade. É difícil sentir-se reconhecido quando não se reconhece o seu sentido de responsabilidade.

As estratégias coletivas de defesa são construídas para fazer face às incertezas, ao sofrimento, à insatisfação e à falta de sentido do trabalho e se caracterizam por condutas de engajamento e mobilização no trabalho, forte coesão de equipe, aumento da carga de trabalho através da aceleração e hiperatividade, recusa em tomar conhecimento de anomalias que não sejam de seu setor, autonomia do coletivo de um setor em relação aos outros setores da empresa, fuga no trabalho para não ceder ao sofrimento, condutas de exposição ao risco com demonstração de coragem e virilidade frente ao grupo.

A nossa opção pela metodologia da Psicodinâmica do Trabalho exigiu que fizéssemos algumas adaptações na sua proposta original. Um dos pressupostos desta metodologia é de que a pesquisa deve partir de uma demanda do grupo que está vivenciando o problema a ser pesquisado (Dejours, 1987, 1992), portanto, os sujeitos da pesquisa são os próprios demandantes. Na realidade brasileira, no entanto, a demanda de pesquisas, por iniciativa dos trabalhadores, ainda é muito rara, e entendemos que esta questão não pode tornar-se um limitador para a realização de investigações, nem para a utilização de uma metodologia que tem se mostrado útil na compreensão da vivência subjetiva no trabalho.

A coleta de dados nos grupos foi realizada através de seis reuniões com os caixas, fora do horário de trabalho, mas dentro do ambiente da agência, com duração aproximada de uma hora cada reunião.

$\mathrm{Na}$ primeira reunião, foram apresentados os temas gerais da pesquisa e um roteiro de questões a serem abordadas nas reuniões subsequentes, que poderiam sofrer alterações caso eles desejassem. Nas reuniões subsequentes foi solicitado aos caixas que falassem de seu trabalho, das mudanças que vêm ocorrendo na empresa e das implicações dessas mudanças nas suas vivências no trabalho, estimulando-se sobretudo os 
Merlo, A.L.C.; Barbarini, Neuzi. "Reestruturação produtiva no setor bancário brasileiro e sofrimento dos caixas executivos: um estudo de caso"

comentários verbais, as discussões informais a respeito dos temas abordados, ou seja, buscou-se que eles falassem de seus sentimentos e percepções e não necessariamente de informações objetivas, pois como ressalta Dejours (1992, p.145), "a justeza da interpretação não está relacionada à objetividade do sofrimento ou à objetividade de uma realidade, causa do sofrimento, mas diz respeito sobretudo à verdade de uma relação dos trabalhadores com seu trabalho, e de uma relação com o coletivo de trabalho".

Quando necessário, procuramos interpretar as questões que não estavam muito claras, submetendo-as novamente ao grupo, na tentativa de suscitar novas discussões, tomando cuidado para não expor sofrimentos e defesas que pudessem se tornar intoleráveis aos trabalhadores. As questões individuais, embora estivessem necessariamente envolvidas nas discussões, não foram tratadas na pesquisa. $\mathrm{O}$ foco foi o coletivo em sua relação com o trabalho, e não problemáticas individuais.

Ao final de cada reunião, que foram gravadas, fizemos também um registro de nossas percepções e sentimentos sobre a dinâmica da reunião, que também se constituiu em material para análise posterior, levando em conta que a dimensão subjetiva do sofrimento psíquico só pode ser recolhida através da subjetividade do pesquisador.

$\mathrm{O}$ tratamento do material de pesquisa foi feito levando em conta a impossibilidade de objetivação dos dados. A análise constituiu, então, em um ir e vir entre as informações transcritas das reuniões com o grupo e as impressões que foram sendo anotadas durante as reuniões, buscando dar um encadeamento aos temas discutidos, sem, no entanto, perder a dimensão da subjetividade do que foi expressado pelos caixas.

A validação foi feita em conjunto com os caixas pesquisados, através da apresentação e discussão da síntese dos resultados da pesquisa (enviado previamente aos participantes), em uma reunião agendada especificamente para este fim, durante a qual foram avaliadas as reações dos caixas aos resultados e procedidas as modificações julgadas necessárias. A participação na pesquisa foi voluntária e a concordância dos participantes com os termos da pesquisa foi registrado através de um Termo de Consentimento Pós-Informado.

\section{SUJEITOS}

A definição do público-alvo, os caixas executivos de uma agência bancária, deu-se à partir de observações e da vivência de um dos autores, 
trabalhador no mesmo banco, onde foi percebido que o exercício desta função estava sendo fortemente influenciada pelas reestruturações ocorridas no banco.

Os sujeitos da pesquisa foram caixas executivos de uma mesma agência, num total de 6 pessoas. Todos os caixas participantes exerciam esta função de forma contínua ou não, há mais de 10 anos. 50\% dos entrevistados possuíam curso superior e os demais o curso secundário completo (atual ensino médio). O grupo já trabalhava junto há bastante tempo alguns há mais de 10 anos -, e o componente com menos tempo já integrava o grupo há mais de 3 anos.

Para preservar o sigilo, todos os nomes foram alterados e, para efeito de apresentação, será utilizada a seguinte identificação:

- Antonio - 36 anos - 11 anos de empresa

- Salete - 42 anos - 11 anos de empresa

- Denise - 44 anos - 20 anos de empresa

- Isabel - 42 anos - 20 anos de empresa

- Berenice - 49 anos - 20 anos de empresa

Visando conhecer melhor a empresa foram reunidas informações sobre o seu funcionamento e sobre as últimas reestruturações ocorridas ou em curso, utilizando pesquisa documental e entrevistas com empregados de áreas responsáveis pela implementação das mudanças e também da área de Saúde e Bem-Estar da empresa.

Foram feitas, também, visitas à agência, em horário de atendimento ao público, para tomar contato com o ambiente e a dinâmica das atividades desenvolvidas, de forma a ter mais familiaridade com os aspectos específicos do trabalho abordados durante as reuniões, e, também, para ter uma representação visual das condições de trabalho.

\section{CARACTERIZAÇÃODA INSTITUIÇÃO PESQUISADA}

A instituição pesquisada, denominada neste artigo de Banco Popular, é um banco público que atua com operações típicas de um banco comercial e também como executor de ações sociais do Governo Federal.

Em 1989, houve uma expansão das atividades da empresa, que modificou expressivamente sua forma de funcionamento. Por autorização do Banco Central do Brasil, passou a atuar como banco múltiplo, com um incremento de atividades voltadas para o mercado financeiro, entrando em concorrência direta com os demais bancos atuantes no mercado.

A atuação como banco múltiplo exigiu dos empregados uma mu- 
Merlo, A.L.C.; Barbarini, Neuzi. "Reestruturação produtiva no setor bancário brasileiro e sofrimento dos caixas executivos: um estudo de caso"

dança de postura; passou-se a exigir uma atitude mais ativa de busca de clientes e vendas de produtos que até então não eram prioritários na atuação do Banco.

Dentre os processos de reestruturação desencadeados pela empresa destacam-se a criação de um programa de Qualidade Total, denominado PQC, programa que não chegou a ser implementado na sua totalidade e o Plano de Racionalização e Competitividade (PRC), baseado nos princípios da reengenharia, que provocou uma revisão completa da forma de atuação do banco, com descentralização administrativa, enxugamento de unidades, redistribuição de processos, realocação de empregados, Planos de Demissão Voluntária, incentivos à aposentadoria, readequação física das instalações, terceirização de processos e outras mudanças ainda em curso até o término desta pesquisa. Estava, ainda, em implantação um Modelo de Segmentação, que buscava estratificar os clientes por faixas de renda e volume de negócios, alterando a estrutura de funcionamento das agências.

Até o mês de julho de 2000, o Banco Popular possuía 55.323 empregados efetivos, distribuídos nas carreiras administrativa, profissional e de serviços gerais (em extinção), além de contar com mais 40.688 pessoas trabalhando em suas dependências, distribuídas entre menores auxiliares (office-boy), estagiários e prestadores de serviço (terceirizados).

A função de caixa executivo, na qual foi enfocada a pesquisa, era considerada, até 1998 uma função de confiança de caráter técnico, quando passou a ser considerada uma função em extinção, o que significa que, a partir dessa data, os empregados que porventura viessem a ser desligados da função por qualquer motivo (demissão, aposentadoria, transferência, realocação para outras atividades) não seriam substituídos por caixas efetivos.

\section{RESULTADOS}

As mudanças mais significativas relacionadas ao sofrimento psíquico ligado ao trabalho, apontadas pelos caixas executivos, são: o congelamento dos salários; o direcionamento dos clientes para outros canais de atendimento; a redução do número de caixas executivos; as ameaças de demissão e a introdução de novas tecnologias. Assim, partiremos desses itens e não de categorias próprias à Psicodinâmica do Trabalho para a interpretação dos resultados, porque isso nos permite uma análise que toma por base a perspectiva dos próprios trabalhadores. 
Psicologia \& Sociedade; 14 (1): 103-122; jan./jun.2002

\section{CONGELAMENTO DOS SALÁRIOS}

Após a implantação do Plano Real em 1994, não houve aumento de salário no banco pesquisado, mas somente alguns abonos anuais que não cobriram as perdas da inflação e não possuem reflexo nos outros benefícios recebidos pelos empregados. Como esses empregados ingressaram no banco em uma época em que a estabilidade e os bons salários eram os principais atrativos, a queda do padrão de vida provocada pelo congelamento salarial foi considerada como um fator de desmotivação e frustração, sentida como perda do valor enquanto profissionais, além de provocar endividamento, transformando-se em um fator adicional de preocupações.

Há um reconhecimento por parte dos entrevistados de que seus salários, apesar das perdas, ainda estão acima da média de mercado, principalmente se comparados com os empregados terceirizados no mesmo banco, que ganham cerca de $1 / 4$ do salário de um caixa executivo. Ao fazer essa comparação, os caixas, mesmo sentindo-se injustiçados com as perdas salariais, mostram-se desconcertados de estarem reclamando, como se não devessem expressar esses sentimentos, demonstrando uma sentimento de culpa e vergonha em relação aos trabalhadores que vivem em situações mais precárias, mesmo reconhecendo que não foram eles que provocaram a precariedade.

\section{DIRECIONAMENTO DE CLIENTES PARA OUTROS CANAIS DE ATENDIMENTO}

Com a implantação de um novo modelo de atendimento que direciona o cliente para canais alternativos de atendimento; como a utilização da internet, da rede lotérica ou das salas de auto-atendimento, os caixas são obrigados a recusar algumas operações no guichê. Esta recusa provoca o sentimento de estarem prestando um mau serviço e trabalhando contra si mesmos, pois o redirecionamento pretende reduzir cerca de $80 \%$ das operações nos caixas.

Além desse sentimento, os caixas acusam um grande número de reclamações dos clientes que chegam ao guichê e não são atendidos. $\mathrm{Na}$ fala de Sílvio, eles deixam de ser a "vitrine" da agência, para tornarem-se o "pára-choque", ou seja, aqueles que antes eram os que apresentavam os serviços do banco para o cliente, agora são os que "seguram" as reclamações e as pressões.

Essa perda de contato com o cliente, que vem se configurando 
Merlo, A.L.C.; Barbarini, Neuzi. "Reestruturação produtiva no setor bancário brasileiro e sofrimento dos caixas executivos: um estudo de caso"

com a implantação do novo modelo de atendimento, pode ser considerada como uma das principais fontes de sofrimento para os caixas e um dificultador na compreensão das mudanças. Ao se verem impedidos de cumprir sua função de atender bem ao cliente e serem reconhecidos por isso eles se vêem "fazendo a própria caveira" (Denise), isto é, estão contribuindo para a extinção da atividade que exercem.

Para o caixa, o principal fator de quebra da monotonia no trabalho é o contato com os clientes, pois cada pessoa atendida traz um elemento novo, um cumprimento, alguns segundos de conversa, algumas dúvidas ou problemas a serem resolvidos, que funcionam como um diferencial na rotina diária. Atender bem ao cliente é fonte de satisfação e, para realizar esse atendimento, os caixas criaram uma série de procedimentos e estratégias ao longo dos anos que lhes permitiu o reconhecimento como profissionais. Ao desprezar essa experiência acumulada, o banco está provocando uma crise de identidade profissional.

\section{REDUÇÃO DO NÚMERO DE CAIXAS EXECUTIVOS}

A redução do número de caixas, agravada por outros fatores contingenciais, como compensação de horas extras que retiram mais caixas do guichê, contribui para aumentar a carga de trabalho e dificulta a compreensão dos objetivos da empresa.

$\mathrm{O}$ cliente mal atendido, que espera muito tempo na fila, descarrega sua irritação ao chegar ao guichê, o que contribui para aumentar o sofrimento. A pressão da fila dificulta também a realização de vendas de produtos, atividade que eles apreciam por permitir o desenvolvimento de estratégias, o uso da criatividade, o planejamento das atividades e que fica impossibilitada quando a fila está muito grande.

Mesmo quando existia pressão para a realização de vendas, a atividade era considerada prazerosa, além de trazer, também, uma compensação financeira, em forma de comissão, como relata Antonio: "a gente antes tinha essa pressão da venda, mas também era uma coisa que retornava para nós em comissão né, legal, a gente tinha a opção de fazer, né”.

A identificação dos caixas com a atividade de vendas pode ser traduzida em números, pois, segundo Sílvio, $80 \%$ das vendas da agência são feitas pelos caixas e na planilha de acompanhamento de vendas existente na agência, os primeiros colocados são sempre os caixas. Com a redução da possibilidade de realizar as vendas eles estão perdendo aquilo que, por um longo período, contribuiu para defini-los como profissionais, 
eles estão perdendo terreno nos seus esforços para manter a relação que têm com o trabalho e o sofrimento está estreitamente ligado a essa desestruturação do saber acumulado.

Outro fator que preocupa os caixas é a falta de critérios para dispensa da função, pois geralmente prevalecem fatores financeiros e não de competência no exercício da função, e há o sentimento de serem tratados como números e de que valores essenciais do relacionamento humano podem, a qualquer momento, ser descartados por uma planilha de custo. Para descrever essa situação, os caixas utilizaram expressões como "fazendo terrorismo", "apavorada", "abalado", "ir para a cadeira elétrica", o que denota uma vivência de medo e ansiedade.

\section{AMEAÇAS DE DEMISSÃO}

A mesma ansiedade da falta de critérios para tirar da função surge, também, em relação às ameaças de demissão que vêm sendo veiculadas na empresa. Os empregados do Banco popular são contratados mediante concurso público e, por esse motivo, possuem uma estabilidade que, mesmo não sendo garantida por lei (os empregados são contratados pelo regime da CLT - Consolidação das Leis do Trabalho), sempre existiu uma tradição de que empregado concursado não seria demitido.

Com as reestruturações na empresa e a tendência a reduzir cada vez mais seu quadro funcional, foi regulamentada normativamente pelo banco a demissão imotivada, sinalizando para uma possível quebra da tradição de estabilidade e existe atualmente entre os caixas, o medo de que o fator custo venha a ser o único critério para as demissões,

A possibilidade de perder o emprego gera uma preocupação constante, mesmo não existindo ainda demissões concretas. Essas preocupações se acentuaram quando a empresa implantou o Programa de Demissão Voluntária (PADV), que sinalizava para futuras demissões sem justa causa, o que foi sentido como uma grande ameaça.

O PADV provocou uma desestabilização das defesas do grupo, pois expôs ainda mais a fragilidade e a precariedade do trabalho, e o sentimento que predomina nesse contexto é o de impotência diante da evolução das mudanças e, mesmo o grupo tendo uma postura questionadora, não há uma mobilização coletiva forte e organizada o suficiente para fazer face às mudanças e propor alternativas, observando-se apenas questionamentos bastante queixosos pela condição de trabalho perdida. 
Merlo, A.L.C.; Barbarini, Neuzi. "Reestruturação produtiva no setor bancário brasileiro e sofrimento dos caixas executivos: um estudo de caso"

\section{INTRODUÇÃO DE NOVAS TECNOLOGIAS}

Das reestruturações ocorridas na atividade do caixa executivo, a informatização pode ser considerada uma das mais significativas. Hoje, os terminais de caixa não são mais simples máquinas autenticadoras, são computadores ligados em rede que processam todas as operações on-line e permitem o acesso à grande parte das informações necessárias para o desenvolvimento das atividades. Esse aspecto faz com que os caixas reconheçam que, apesar de a tecnologia ser um dos instrumentos utilizados para substituição de mão-de-obra, ela trouxe muitas facilidades para o diaa-dia, permitindo ao caixa executivo fazer um atendimento completo ao cliente, sem necessidade de encaminhá-lo a outros setores da agência.

No entanto, mesmo reconhecendo o valor da tecnologia, permanecem algumas ressalvas quanto ao seu uso. A tecnologia tende a dissimular o trabalho real, fazendo com que uma atividade pareça ser simples quando na realidade não o é. Uma autenticação de documento, por exemplo, é uma tarefa aparentemente simples, mas que exige do caixa toda uma aprendizagem que envolve o reconhecimento do documento, a memorização de códigos de lançamento contábil, o manuseio do terminal de autenticação, o domínio de softwares e sistemas, o desenvolvimento de formas de trabalhar bem com a máquina, atividades que não são percebidas em uma análise rápida. Esses esforços permanecem invisíveis, são tratados como "naturais", e a impressão que fica é a de que são os computadores que fazem o trabalho. O que não é conhecido passa por inexistente e, portanto, não é passível de reconhecimento. As ressalvas dos caixas quanto ao uso das máquinas ocorrem, em grande parte, devido a essa invisibilidade que minimiza a importância do caixa e torna-o passível de substituição.

Com a implantação de novos sistemas houve também o aumento da necessidade de digitar documentos no guichê de caixa, fator considerado como um dos responsáveis pelo alto índice de Lesões por Esforços Repetitivos/Distúrbios Ostemusculares Relacionados ao Trabalho (LER/ DORT) entre os caixas, principalmente quando aliados ao aumento da pressão no trabalho e à necessidade de estender a jornada de trabalho e suprimir as pausas nos dias de maior movimento.

Alguns fatores, como a invisibilidade das LER/DORT suscita dúvidas e desconfiança entre os caixas, principalmente em relação àqueles que assumem a doença, e o medo das consequiências que podem advir do reconhecimento da doença, faz com que os caixas recorram à estratégia 
coletiva do silêncio, negando o sofrimento dos outros e calando sobre o próprio.

\section{RISCOS DAATIVIDADE}

O excesso de clientes na fila faz com que os caixas suprimam procedimentos de segurança, expondo-se a riscos financeiros e a punições por erros cometidos. Operações como a entrega de talões de cheques sem provisão de fundos, realização de pagamentos sem conferência de assinaturas são comuns nessas circunstâncias, tornando-se uma estratégia defensiva que não traz propriamente o prazer, pois ela é carregada de tensões. A sua vivência é relatada como uma necessidade, pois, se eles não a praticassem, as conseqüências seriam ainda mais difíceis de suportar.

O risco de recebimento notas falsas também é aumentado com as mudanças, principalmente com a terceirização dos serviços de retaguarda, pois os empregados da empresa terceirizada responsáveis pela manutenção em papel-moeda dos caixas-eletrônicos não recebem a mesma formação que caixas executivos e estes consideram que podem deixar passar essas notas.

Os caixas destacam a importância da experiência na detecção de notas falsas, pois estas estão cada vez mais sofisticadas e informações teóricas não são suficientes. O conhecimento informal, adquirido com a prática, em alguns casos, é a única garantia que os caixas possuem para assumir um risco, e a fragmentação das tarefas, com a introdução de terceirizados, contribui para aumentar o risco no trabalho.

\section{ESTRATÉGIAS DE DEFESA}

A principal estratégia de defesa utilizada pelos caixas é a grande coesão do grupo. Eles possuem praticamente a mesma formação e compartilham as mesmas estratégias, o que possibilita a diminuição do risco no trabalho. A relação de confiança existe porque eles compartilham as mesmas regras. Os improvisos, as burlas e as trocas não ocorrem ao acaso, mas porque sabem que o outro trabalha sob o mesmo conjunto de regras e se surge alguma operação nova no guichê, um indaga ao outro como ela deve ser executada e, caso ninguém saiba, eles tentam descobrir juntos, como explica Isabel: "se chega alguma coisa que eu não sabia, eu já pergunto para alguém. Aí a gente se ajuda um ao outro, se ninguém sabe, a gente vai atrás, mas sempre tem um que já viu alguma vez, já tem uma idéia, 
Merlo, A.L.C.; Barbarini, Neuzi. "Reestruturação produtiva no setor bancário brasileiro e sofrimento dos caixas executivos: um estudo de caso"

aí tu já tem um começo".

Essa coesão do grupo é uma estratégia coletiva de defesa que garante, ao menos por enquanto, a proteção contra os efeitos do sofrimento sobre a saúde, pois permite as trocas, a transmissão de conhecimentos e descobertas, defesa esta que pode ser enfraquecida com o desestruturação que vem ocorrendo com o grupo. provocando sentimento de carência entre os que saem e nostalgia do tempo em que ser caixa significava alguma coisa, entre os que ficam.

Uma outra estratégia de defesa pode ser demonstrada através do medo de assumir novas funções na empresa. Em virtude da implantação do novo modelo de funcionamento das agências, o número de gerentes está aumentando, surgindo várias oportunidades de promoção, mas, mesmo se autodefinindo como bons vendedores - requisito principal para assumir funções gerenciais - essas oportunidades não se mostram atrativas, porque a pressão para o corpo gerencial é ainda maior do que a pressão para os caixas e, assim, assumindo a função, o empregado se vê obrigado a fazer coisas com as quais não concorda, além de trabalhar em um ritmo ainda mais acelerado do que a atividade de caixa executivo.

O prazer que o aumento de salário e de poder que a função gerencial traz é anulado pela perspectiva de se verem obrigados a tomar decisões que contrariam suas convicções e serem pressionados pelo cumprimento de prazos e metas que mudam a qualquer momento. Os caixas valem-se aqui da defesa contra o sofrimento ético (Dejours, 1998), recusando-se a trair seus próprios valores em nome do atingimento de metas. Manter-se como caixa é preservar esses valores que o envolvimento gerencial não permite mais.

O caixa tenta manter uma existência que vai além de questões financeiras ou de status, ele tenta manter uma representação simbólica do seu trabalho, pois, ao desvalorizar a atividade de caixa, desvaloriza-se também a pessoa que a exerce, surgindo o medo de não ser qualificado o suficiente para assumir outras funções, mesmo se sentindo intelectualmente capaz de realizar um trabalho mais criativo, com um salário melhor.

\section{DISCUSSÃO}

Nesse estudo feito com os caixas executivos constatamos que a mobilização psíquica provocada pelas mudanças é intensa. O cotidiano desses trabalhadores está permeado por sentimentos de insegurança, estranhamento, desorientação e impotência, diante das incertezas das pro- 
postas da empresa.

A insegurança relaciona-se sobretudo com as incertezas quanto ao futuro, pois a extinção da função de caixa executivo vem sendo colocada em prática com rapidez, e as medidas de racionalização de processos, terceirização, regulamentação da demissão sem justa causa e implantação de programas de demissão voluntária, indicam que no futuro não haverá postos de trabalho suficientes para todos os trabalhadores que compõem o quadro atual da empresa.

As mudanças implantadas são percebidas como contraditórias, provocando um sentimento de desorientação. A dificuldade de compreensão se dá, porque a lógica das mudanças propostas não se reporta às questões do trabalho e sim a questões econômicas, que é uma racionalidade distante da realidade do trabalho em si.

A perda do contato com o cliente é uma das maiores fontes de sofrimento para o grupo, na medida em que esse contato permite uma quebra da rotina, onde o cliente geralmente traz o elemento surpresa - enigmático, para se usar uma categoria da Psicodinâmica do Trabalho - da atividade do caixa. São as demandas dos clientes que vão proporcionar aos caixas a oportunidade de exercer a criatividade no trabalho, principalmente através das vendas, atividade que permite o desenvolvimento de estratégias, de planejamento, de novas formas de abordagem, e o contato humano, proporcionando a obtenção de prazer no trabalho.

O sentimento de desvalorização é manifestado também nas queixas sobre o achatamento salarial - que os obriga a baixar o nível de vida a que estavam habituados - na perda do status que a função proporcionava, e na desestruturação de um saber acumulado ao longo dos anos de exercício da função. Este saber, construído pelo caixa através do seu confronto com o real do trabalho, está sendo fragmentado e repartido entre diversos executores, muitos deles empregados terceirizados.

O desprezo da empresa pela atividade de caixa, leva à degradação da imagem de si e ao surgimento de um discurso desvalorizante. A metáfora utilizada pelos caixas, na qual eles se dizem passando do status de "vitrine" para o de "pára-choque", denota a substituição do sentimento de realizar um trabalho nobre, para o de realizar um trabalho bruto e de pouco valor social. A perda de referências e a desestruturação progressiva dos valores do trabalho bem feito, provoca uma crise de identidade profissional e os trabalhadores passam a não se reconhecer mais no que fazem.

No medo de assumir funções gerenciais os caixas também demonstram uma preocupação ética, que é o medo de verem-se obrigados a 
Merlo, A.L.C.; Barbarini, Neuzi. "Reestruturação produtiva no setor bancário brasileiro e sofrimento dos caixas executivos: um estudo de caso"

executar ordens que contrariam seus princípios. Essa preocupação indica uma necessidade de manter uma certa integridade, mesmo num ambiente adverso, pois essa dimensão se relaciona àquilo de si que é colocado em jogo no trabalho. Essa resistência exige também um gasto de energia que, após um tempo, pode fazê-los a ceder às pressões, para conseguirem satisfazer outras necessidades mais prementes, como a de se manter no emprego, por exemplo.

Mesmo com todas as pressões, os caixas ainda conseguem obter prazer no trabalho, e este prazer vem principalmente da autonomia conquistada pelo grupo, que permite a tomada de decisões referentes às tarefas desenvolvidas no guichê, seja na resolução de problemas, na criação dos próprios controles e na criação de novas formas de fazer uma atividade, adiantando-se, muitas vezes, às decisões gerenciais. Esse espaço de manobra, entre a organização de trabalho prescrita e a organização do trabalho real, existente no trabalho dos caixas, aliado ao reconhecimento gerencial pelas decisões tomadas, garantem a obtenção de prazer no trabalho.

A autonomia de decisões só é possível por existir uma grande coesão no grupo, o que garante que as decisões serão cumpridas por todos. Essa coesão é uma estratégia de defesa utilizada pelo grupo, e, através dela, eles unem suas forças para lutar contra as adversidades do dia-a-dia, para resolver problemas e criar soluções em conjunto. As decisões tomadas, no entanto, podem também ser causa de sofrimento, pois muitas delas envolvem riscos para os empregados, ameaçando a sua integridade. Esses riscos podem ser financeiros, como o risco de perdas ou de repreensão por uma operação mal feita, ou riscos para a saúde, com a exposição a situações que podem provocar o adoecimento pelas LER/DORT.

Para concluir, podemos dizer que o sofrimento psíquico dos caixas executivos, provocados pelas reestruturações no trabalho, atingem níveis preocupantes. As novas formas de organização do trabalho estão destruindo a imagem do caixa como um profissional e reduzindo a possibilidade de serem reconhecidos pelo exercício da atividade. Esse estreitamento das possibilidades de obter reconhecimento no trabalho já começa a apresentar sinais de alerta, pois as estratégias de defesa mostram-se próximas do limite da eficácia. Alguns desses sinais são o sentimento de que o trabalho fica a cada dia mais pesado, as dúvidas quanto à qualificação para exercer outras atividades e o uso de expressões depreciativas, como, por exemplo, aquela em que eles se comparam a um pára-choque.

Esse sofrimento é devido, em grande parte, à subestimação do 
Psicologia \& Sociedade; 14 (1): 103-122; jan./jun.2002

fator humano pela administração da empresa, e a evolução deste quadro dependerá de quanto espaço a nova organização de trabalho estará oferecendo para que esses empregados exerçam a criatividade, façam experimentações e transformem o novo ambiente de trabalho.

\section{REFERÊNCIAS BIBLIOGRÁFICAS}

DANIELLOU, F.; LAVILLE, A.; TEIGER, C. Ficção e realidade do trabalho operário. Revista Brasileira de Saúde Ocupacional, v. 17, n. 68, p.7-13, 1989.

DEJOURS, C. La méthodologie en Psychopathologie du Travail. IN: Dejours, C. (coord.) Plaisir e souffrance dans le travail. Séminaire interdisciplinaire de Psychopathologie du Travail, Paris: Ed. de l'AOCIP, 1987. Tome I, p. 99-113.

A Loucura do Trabalho. São Paulo: Oboré/Cortez, 1992.

Soufrance en France: La banalisation de l'injustice sociale. Paris: Seuil, 1998.

GARCIA, M. de F. Reestruturação bancária no Brasil nos anos 90 e os efeitos sobre as relações de trabalho: Algumas evidências recentes. VI Encontro Nacional de Estudo do Trabalho, ABET, Belo Horizonte, 1999.

GRISCI, C. L. I. Trabalho, tempo e subjetividade: a reestruturação do trabalho bancário. Porto Alegre, 2000. 314p. Tese (Doutorado em Psicologia) - Programa de Pós-Graduação em Psicologia. Pontifícia Universidade Católica do Rio Grande do Sul.

JINKINGS, N. O mister de fazer dinheiro: Automatização e subjetividade no trabalho bancário. São Paulo: Boitempo, 1995.

LARANGEIRA, S. M. G. Reestruturação produtiva no setor bancário: A realidade dos anos 90: Educação e Sociedade. Campinas. Ano XVIII, p.111138, dez. 1997. 
Merlo, A.L.C.; Barbarini, Neuzi. "Reestruturação produtiva no setor bancário brasileiro e sofrimento dos caixas executivos: um estudo de caso"

MERLO, A. R. C. A informática no Brasil: prazer e sofrimento no trabalho. Porto Alegre: Ed. da Universidade/UFRGS, 1999.

SEGNINI, L. R. P. Mulheres no trabalho bancário. São Paulo: EDUSP, 1998.

Álvaro Roberto Crespo Merlo é professor do Programa de PósGraduação em Psicologia Social e Institucional e Programa de PósGraduação em Epidemiologia, Centro de Documentação, Pesquisa e Formação em Saúde e Trabalho (CEDOP), Dep. de Medicina Social, Faculdade de Medicina, Universidade Federal do Rio Grande do Sul; Ambulatório de Doenças do Trabalho/SMO do Hospital de Clínicas de Porto Alegre.O endereço eletrônico do autor é: merlo@ufrgs.br

Neuzi Barbarini é mestre pelo Programa de Pós-Graduação em Psicologia Social e Institucional, Universidade Federal do Rio Grande do Sul. O endereço eletrônico da autora é: neuzi@brturbo.com

Álvaro Roberto Crespo Merlo e Neuzi Barbarini Reestruturação produtiva no setor bancário brasileiro e sofrimento dos caixas executivos: um estudo de caso.

Recebido: $17 / 5 / 2002$

$1^{\text {a }}$ revisão: $1^{\circ} / 7 / 2002$

Aceite final: 16/8/2002 